\title{
Computer-aided self-observation psychological stressors in an ICU
}

\author{
R. Malacrida, D. Bomio², R. Matathia², P.M. Suter' \& M. Perrez ${ }^{2}$ \\ Ospedale San Giovanni, Switzerland; 'Hôpital Cantonal et Universitaire, Geneva, Switzerland, \\ ${ }^{2}$ Institut de Psychologie Université de Fribourg, Switzerland
}

Accepted 10 July 1991

Key words: intensive-care units, psychological stress, continuing nursing education, computer programs

\section{Summary}

We have developed a procedure for a computer-aided self-observation method in stressful situations. Staff members of an ICU recorded their experiences on a computer placed in the ICU, immediately after having experienced a stressful event. The computer asked for and stored psychologically relevant information about cognitive, affective and behavioural aspects. An external stress memory of an ICU was established, allowing a personal/institution-orientated stress diagnosis to be made on the basis of 192 episodes.

Sixteen nurses in an intensive care unit in a Swiss hospital used this methodology for 12 weeks. One hundred and ninety-two stressful events were recorded (12 episodes per person), forming a good sample of the stressful episodes for the unit. To the same 16 nurses and 31 nurses at the same hospital $(\mathrm{N}$ total $=47)$ the Nursing Stress Scale was administered. The results from both groups showed that problems dealing with death and work load were predominant. Nurse characteristics such as levels of training (unskilled, skilled) and experience (number of years working as a nurse) were analysed by different statistical procedures and related to their stress experience.

\section{Introduction}

Several contributions focussing on stress levels in nursing staff working in intensive care units have been published [1-7]. Mohl compared the work attitudes and clinical distress of nurses in general medical units with ICU nurses by means of questionnaires. The nurses from the ICUs differed from those of the general medical units in work attitudes but not in the level of clinical stress. These findings suggest that, while the primary nursing task was an important element in determining nursing attitudes, social system variables also contributed substantially. Furthermore, it is well-known that psychological stress in the ICU influences the quality of patients' care [8-10]. Different types of stimuli can induce stress in medical care:
- the physical stimuli resulting from technological instrumentation and the care environment

- social stimuli coming from the disease of patients, from relatives of the patients and from other staff members

- stressors related to work demands and to administration.

Coping with stress is not only influenced by environmental characteristics but also by personal characteristics (training, experience, coping styles, etc.) and the relationship of personal variables to stress experience.[11].

The purposes of the present study were to (i) describe the quality and frequencies of stressors in a hospital setting using a questionnaire and a new method of computer-aided self-observation of stress experience and coping, (ii) correlate differ- 
ent features, such as formation, experience, etc., with stress experience and (iii) to analyse characteristics of the stressful situations in more detail based on computer-aided self-observation.

\section{Method and sample}

Until now psychological data on stress and coping behaviour in care units has been recorded on questionnaires [12]. The existing questionnaire procedures for the recording of stress and coping tendencies of nursing staff have the advantage of great economy but have an uncertain validity. If interviews are used as data-collecting methods, there is a long latency between the stressful encounter and its being recorded. We developed a computer-aided behaviour-recording method $[13,14]$ to enable us to reach a greater validity and to reduce the time between the stressful situation and its recording. We used the personal computer to record highly structured descriptions of stress encounters. The description of enviromental characteristics included a free text of the stressful situation; a subjective perception of changeability and controllability of the situation and other environmental characteristics. Emotional reactions were rated, using six different dimensions [1-6]. Coping operations were differentiated into two groups according to whether they are self-directed and intraphysic (palliation, re-evaluation, self-blame, etc.) or environment-directed (active influences, evasion/withdrawal, passivity towards the use of social support).

All the nurses of the hospital were invited to participate in the study by answering the Nursing Stress Scale (NSS) [15].

Most of the nurses agreed to co-operate (see Table 1). The Nursing Stress Scale (NSS) is a questionnaire asking for frequencies of well-described stressful care situations. The total score was calculated by adding the values of 7 sub-scores (such as stress concerning death and dying of patients, scale 1 , or stress covering conflict with physicians, scale 2 , etc.).

Each nurse started the computer as soon as possible after a stressful episode. The personal com- puter presented a sequence of questions asking for different answers.

The computer-aided self-observation method was applied by 16 of 31 nurses, invited to participate in the study, of an Intensive Care Unit (ICU) and an Urgent Care Unit (UCU) (see Table 1). During a period of 12 weeks 192 stressful events were communicated to the computer and were stored.

The full-time ws. part-time employment and level of professional education (with nursery school, without nursery school and during nursery school) were independent variables. The 'professional experience-variable' was put into 3 categories by the number of years of service as a nurse (less than 5 years, from 5 to 10 years and more than 10 years). The different care units (see Table 1) were also considered as an independent variable.

\section{Results}

Distribution of stressors in the hospital according to the Nursing Stress Scale (NSS) and according to computer-aided self-observation.

Table 2 shows the distribution of stress intensity $(1=$ never, $2=$ occasionally, $3=$ often, $4=$ always) in the 7 different variables of the NSS for the entire sample $(\mathrm{N}=49)$

'Death and dying' (scale 1) had the highest score, followed by 'work load' (scale 6), 'Uncertainty concerning treatment' (scale 7), 'Conflict with physicians' (scale 2) and 'Lack of support' (scale 4). 'Work load' includes stressful situations that arise from staffing and scheduling problems, as well as inadequate time to complete nursing tasks and to support patients emotionally. 'Conflict with other

Table 1. sample.

\begin{tabular}{lll}
\hline & $\begin{array}{l}\text { Nursing } \\
\text { Stress Scale }\end{array}$ & $\begin{array}{l}\text { Computer-aided } \\
\text { self-observation }\end{array}$ \\
\hline General medical unit & $18(0)$ & Not used \\
Intensive care unit (ICU) & $17(1)$ & $13(5)$ \\
Urgent care unit (UCU) & $12(1)$ & $3(10)$ \\
Total & $47(2)$ & $16(15)$ \\
\hline
\end{tabular}




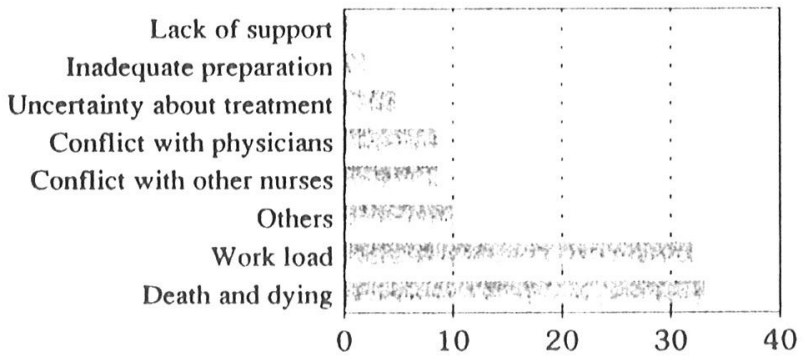

Fig. 1. Percentages of NSS categories for the 192 situations recorded with the computer-aided self-observation.

nurses' (scale 5) reaches the smallest frequency, which may be an indication of a co-operative social atmosphere in the hospital.

The analysis of stress in the ICU and UCU with computer-aided self-observation data, was based on a period of self-observation for 12 weeks. These results provided a more precise characterization of stress and coping with stress in these units (Fig. 1). The contents of the analysis of 192 stressful events using the NSS categories - were stored by the computer and gave the same picture; that death and dying (34\%) and work load (32\%) were the two highest ratings.

Another classification of the 192 recorded events showed that $39 \%$ of the episodes were problems with patients and their families, $35 \%$ were problems with the administration of the ICU and $20 \%$ were problems concerning interpersonal relations (Fig. 2).

A multivariate analysis of variance with the 7 categories of NSS as dependent variables showed a significant difference between the nurses working full-time $(n=35)$ and the nurses working part-time

Table 2. Means and standard deviations of the 7 NSS categories $(n=49)$.

\begin{tabular}{lll}
\hline Categories of NSS & $\mathrm{m}$ & $\mathrm{s}$ \\
\hline Conflict with other nurses & 1.92 & 0.56 \\
Lack of support & 2.04 & 0.73 \\
Inadequate preparation & 2.12 & 0.59 \\
Conflict with physicians & 2.15 & 0.45 \\
Uncertainty about treatment & 2.19 & 0.44 \\
Work load & 2.52 & 0.57 \\
Death and dying & 2.60 & 0.59 \\
\hline
\end{tabular}

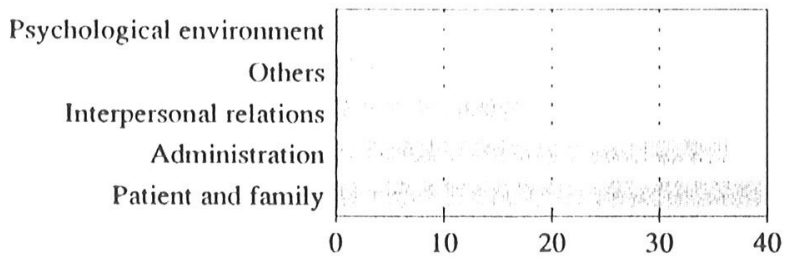

Fïg. 2. Percentages of stress categories for the 192 situations recorded with the computer-aided self-observation.

$(n=14): F_{7.41}=2.8, p=0.02$. The main differences are for Conflict with physicians and Uncertainty about treatment that are felt more strongly by nurses working half-time.

Considering the different care units, the multivariate test of Wilks is also significant $\left(\mathrm{F}_{14,78}=1.9\right.$, $p=0.04)$. Univariate tests are significant for the categories Death and dying $\left(\mathrm{F}_{2.46}=3.4, \mathrm{p}=0.04\right)$ and Work load $\left(\mathrm{F}_{2,46}=4, \mathrm{p}=0.02\right)$, whose values are higher in the General Medical Unit $(n=18)$ and Intensive Care Unit $(n=18)$ than in the Urgent Care Unit $(n=13)$.

For the professional experience, univariate tests showed signifiant differences for the categories Death and dying $\left(\mathrm{F}_{2,44}=4.1, \mathrm{p}=0.02\right)$ and Unvertainty about treatment $\left(\mathrm{F}_{2,44}=3.8, \mathrm{p}=0.03\right)$ : the least experienced nurses (less than 5 years of professional experience, $\mathrm{n}=15$ ) demonstrate more stress than the medium experienced (between 5 and 10 years, $n=17$ ). The most experienced nurses (more than 10 years, $n=15$ ) are the least stressed of all.

Taking the factor professional formation, with the steps 'without' $(n=18)$, 'in training' $(n=8)$ and 'accomplished' $(n=23)$, we find that the group 'in training' shows the highest stress (helplessness) in NSS items describing situations where patients fail to improve and situations with uncertainty regarding the operation and functioning of specialised equipment, i.e. assistance in technically demanding interventions.

Analysis of coping behaviour on the basis of computer-aided self-observation and on the basis of the NSS-data.

The computer-aided self-observation data gave a more sophisticated psychological analysis of the characteristics and processes of coping with stress 
in the observed units. The results were based on a sample of 12 stored episodes for each of the 16 nurses (192 episodes).

As far as psychological interpretation of the stressful situation is concerned, the subjects rated each situation on ambiguity, changeability (which means the probability that the situation will change on its own dynamic), subjective controllability (which means the probability of mastering the situation under one's own influence), valence (subjective intensity of the stressor) and expected reappearance of the stressful event with the results shown in Table 3.

The situations were estimated by the nurses using a 6 point scale on problems of reoccurrence $(x=3,6)$ of high valence $(x=3.30)$, a rather high subjective controllability $(x=2.38)$, with high ambiguity $(x=3.71)$ and low changeability $(x=1.28)$ and with a high expected probability of reoccurrence.

As far as coping tendencies in the nursing unit care were concerned, the results showed that the most important coping strategies employed in the stressful situations were 'activity' and 'take-up support from colleagues'. Both forms of coping were adequate, considering the high estimated controllability of the situations. Passivity and avoidance were low. The most important self-directed coping tendencies were 'search for information', 'palliation' and 're-evaluation'.

\section{Discussion}

The findings underline the importance of three categories of stressors: problems concerning death and dying, problems in the context of work load and problems related to administration. The first type of problem is inherent to the work of the medical care staff. The aim of the hospital is to aid and support patients and their relatives and death and dying are, by their very nature, problems of great concern.

Problems concerning administration and work load, on the other hand, are problems of the institution and must be the first object of intervention in order to ameliorate the functioning of the differ- ent care units. Mohl's data demonstrated that social system variables had an effect on unit nurses' attitudes and even on their stress levels [3]. In particular, he found that high levels of staff support appeared central to reducing stress levels. When considering our results it should be taken into account that in our ICU there has been staff support for many years, which has helped nurses to do a better job and to define their work more clearly and their function more independently and creatively. This is probably the reason why we did not find higher levels of NSS stress in the ICU.

The results show that professional formation and experience influence encounter with stressful events in the hospital, as already observed in 1977 by Porter in the United Kingdom [16]. Gribbins and Marshall [17] also found increased experience developed the personal coping capabilities of the nurses, especially if they had worked for more than three years. Only two stressors did not change with time: under-staffing and working with interns. On the other hand, Bryson and Aderman (1985) [12] showed that there were no significant differences among the work experience levels in job tension and, in addition, they found that the relationship of job satisfaction to the amount of work experience was also not significant.

Our results further demonstrate the importance of being able to cope when faced with stressful situations and also that there are some means of coping which clearly facilitate the mastering of stress.

The computer-aided self-observation system produced interesting information on concrete problems of the ICU and on psychological processes. The external stress memory was accepted

Table 3. Means and standard deviations of the rating of the 192 situations recorded with the computer-aided self-observation.

\begin{tabular}{lll}
\hline & $\mathrm{m}$ & $\mathrm{s}$ \\
\hline Changeability & 1.28 & 1.45 \\
Controllability & 2.38 & 1.70 \\
Valence & 3.30 & 1.21 \\
Reappearance & 3.42 & 1.39 \\
Ambiguity & 3.71 & 1.36 \\
\hline
\end{tabular}


by most staff members, who stored 192 episodes over a period of 12 weeks. These stored episodes allow us to process stress diagnosis not only on the institution but also on individuals.

\section{References}

1. Vreeland R, Ellis GL. Stress on the nurse in an intensive care unit. JAMA 1969; 208(2): 332-4.

2. Casserm NH. Stress on the nurse and therapist in the intensive care unit and the coronary care unit. Heart Lung 1975; 4(2): 252-9

3. Mohl PC, Denny NR, Mote TA, Coldwater C. Hospital unit stressors on nurses: primary task vs social factors. Psychosomatic 1982; 23(4): 336-74.

4. Tyson J, Lasky R, Weiner M, Caldwell T, Summer J. Effect of nursing-staff support groups on the quality of newborn intensive care. Crit Care Med 1984 Oct: 12(10): 901-6.

5. Eisendrath SJ, Link N, Matthay M. Intensive care unit: how stressful for physicians? Crit Care Med 1986 Feb; 14(2): 95-8.

6. Soupios MA, Lawry K. Stress on personnel working in a critical care unit. Psychiatr Med 1987; 5(3): 187-8.

7. Lewis KF, Poppe S, Twomey J, Peltier (i. Survey of perceived stressors and coping strategies among burn unit nurses. Burns 1990 Apr; 16(2): 109-12.

8. Jacobson SF. Stress and coping strategies of neonatal intensive care unit nurses. Res Nurs Health 1983; 6(1): 33-40.

9. Hay D, Oken D. The psychological stresses of intensive care unit nursing. In: Monen A, Lazarus R, editors. Stress and coping. New York: Colombia University Press, 1985: 9)- 9 .

10. Keane $\Lambda$, Ducette J, Adler DC. Stress in ICU and non-ICU nurses. Nurs Res 1985; 34(4): 231-6.

11. Lazarus RS. Psychological stress and the coping process. New York: McGraw-Hill, 1966.

12. Bryson RW, Aderma M, Sampiere JM, Rockmore L Jr, Matsuda T. Intensive care nurse: job tension and satisfaction as a function of experience level. Crit Care Med 1985; 1.3(9): 767-9.

13. Perrez. M, Reicherts $M$. Coping behaviour in the natural setting: a method of computer-aided self-observation. In: Dauwelder JP, Perrez M, Mobi V, editors. Controversial issues in behaviour modification. Amsterdam/Lisse: Swets \& Zeitlinger, 1987: 127-37.

14. Perrez M. Reicherts M. Belastungsverarbeitung: Computerunterstützte Selbsbeobachtung im Feld. Diff Diag Psychol 1988.

15. Gray-Toft P, Anderson JC. The nursing stress scale: development of an instrument. J Behav Assess 3(1): 11-23.

16. Porter SW. Intensive therapy nursing. Inten Care Med 1977; 3(2): 99-103.

17. Gribbins RE, Marchall RE. Stress and coping in the NICU staff nurse: practical implications for change. Crit Care Med 1982; 10(12): 865-7.

Address for offprints:

Dr R. Malacrida,

Centro di Cure Intense,

Ospedale San Giovanni,

CH-650) Bellinzona.

Switzerland 